\title{
The Lived Experience of Australian Women Living with Breast Cancer: A Meta-Synthesis
}

\author{
Lalithambigai Rajagopal $^{1}$, Pranee Liamputtong ${ }^{1,2}$, Kate A. McBride ${ }^{1,3 *}$
}

\begin{abstract}
Background: Breast cancer is the second most common cancer among Australian women. In 2019, an estimated 19,000 women in Australia were diagnosed with breast cancer, with around 3,058 women dying from the disease in the same year. Although many qualitative studies published in Australia exist which examine breast cancer from various perspectives, only limited literature is available which addresses Australian women's lived experience of breast cancer from diagnosis, treatment and beyond. Method: Meta-synthesis of qualitative studies. Participants who took part in either semi-structured interviews or surveys with open-ended questions were included. A thematic synthesis analysis approach was used. Results: Five themes and 13 sub themes emerged from the data analysis which illustrated the lived experience of Australian women diagnosed with breast cancer. Emotional burden and women's response towards their breast cancer diagnosis were key themes. Experience of decision- making, social distress, symptoms beyond changes in their body, fertility considerations and their role as mothers were some of the challenges during their treatment. Women coped and adjusted with these challenges through the support of their family, and healthcare providers. Women developed greater empowerment by making their life choices after treatment. Life choices such as getting into a new relationship was challenging for single women. Conclusion: Although most women were emotionally supported following their diagnosis, there are still areas where women could be better supported such as when having to break the news of their breast cancer diagnosis to their children, provision of ongoing emotional support for caregivers of women with breast cancer, providing constant emotional and informational support at the point of diagnosis and during their treatment, tailoring treatments according to different stages of pregnancy, and discussion of fertility treatments in timely manner by healthcare professionals.
\end{abstract}

Keywords: breast neoplasm- life experiences- social support- qualitative research- decision- making- Australia

Asian Pac J Cancer Prev, 20 (11), 3233-3249

\section{Introduction}

Breast cancer is one of the most common causes of mortality among women globally and is most commonly diagnosed cancer among Australian women (Australian Institute of Health and Welfare [AIHW], 2019). The risk of developing breast cancer before the age of 85 years old is one in eight in Australia. In 2019, it is estimated that $\sim 19,000$ women in Australia will be diagnosed with breast cancer, with 3,058 women dying from the disease (AIHW, 2019). The overall breast cancer survival rate for women in therefore high with a five-year survival rate of $90.8 \%$ and ten-year survival rate of $83 \%$, though breast cancer in pre-menopausal women has poorer outcomes than in older post-menopausal women (Breast Cancer Netwrok Australia [BCNA], 2019).

Over the last 20 years, multiple qualitative studies have been published in Australia examining breast cancer from various perspectives. We found multiple studies on breast cancer experiences from both psychosocial and medical perspectives. We also found studies on the meaning of breast cancer, as well as coping challenges during treatment and interpretations of mortality in the context of breast cancer. A few studies focussing on breast cancer experiences for mothers, rural and young women or within a specific cultural context were also found. Internationally, several studies have examined the lived experiences of women diagnosed with breast cancer. For example, Perreault and Bourbonnais (2005) explored the experience of six Canadian women living with breast cancer, Joulaee et al., (2012) examined the lived experience of breast cancer of Iranian women across all ages and Cebeci et al., (2012) examined Turkish women's lived experience while receiving their chemotherapy treatment. However, only limited literature was available which addressed Australian women's lived experience of breast cancer and their feelings explicitly from diagnosis, treatment and beyond.

Given the uniqueness of the Australian healthcare system and the country's unique demographic 
characteristics in terms of multiculturalism, understanding the lived experience of Australian women with breast cancer in this meta-synthesis may allow health care providers in the Australian healthcare system to understand these experiences to a greater depth. This in turn may help facilitate greater sensitivity when treating their patients. This is particularly important given that the complexity and intensity of breast cancer treatment has increased in recent years, thereby imposing greater challenges on the lives of women undergoing treatment for breast cancer (Stout et al., 2012). Health care providers need to understand the meaning of this lived experience of breast cancer from the perspective of Australian women in order to design appropriate interventions to reduce and/or prevent distress in these women in the unique Australian healthcare setting.

The aim of this meta-synthesis is therefore to draw on the findings of qualitative research studies that have investigated breast cancer to provide a better understanding of Australian women's experiences of the disease and associated treatments, thereby incorporating women's views and perspectives to inform recommendations for healthcare policy and practice as well as future research.

\section{Materials and Methods}

\section{Inclusion and exclusion criteria}

For articles to be included in this meta-synthesis, the study needed to meet the following criteria: (a) be related to lived experiences of female individuals with breast cancer (b) utilised a qualitative methodology (c) the patients' perspectives were explored (d) the sample were from and living in Australia (e) was published in English. Grey literature was excluded.

\section{Search strategy}

A broad electronic search of the literature was conducted using Medline, Embase, CINAHL and PsycINFO between May 2017 and September 2017. Key words were included in the search in combination with MeSH (medical subject headings). The initial search found 436 articles (172 from Medline, 141 from Embase, 101 from PsycINFO and 22 from CINAHL), with 324 articles remaining for consideration once duplicates were removed (Figure 1).

\section{Screening of papers}

Two authors (LR and KM) independently screened all 324 studies' titles and abstracts according to the relevance of their methodology and themes. If the abstract did not provide sufficient information, the full text was read to determine its eligibility. Differences were resolved during team meetings. A challenge was whether or not to include mixed methods studies. After discussion with all authors, we decided not to include any mixed methods studies, except one study, that involved non - open ended questionnaires as they do not contribute any themes, and thus excluded them from analysis. We included one mixed study by Perz et al., (2014) as their online survey involved two open-ended questionnaires which contributed to five themes.

\section{Assessment of Papers - Quality Appraisal}

Evaluating the quality of each included paper is vital to confirm inclusion of the studies that met the criteria, and to ascertain integrity and validity of the data in the studies. We used the Critical Appraisal Skills Programme (CASP) to appraise the quality of the included studies (Lachal et al., 2017). This checklist consists of 10 questions which are used to assess quality of qualitative studies for value and trustworthiness.

To ensure the rigour of the assessment was met, LR examined the full texts of the potentially relevant papers individually using the first two questions of the CASP as an initial threshold which led to the screening out of a further five ineligible studies based on their poor quality (unclear qualitative research methods, or justification and /or explanations). Ineligibility was confirmed with PL and KM (Figure 1).

We adopted a three-point rating system for each of the remaining 8 CASP questions (Moolchaem et al., 2018). The three-point scale ranges from one to three: one is a weak score for articles which little or no justification; two is a moderate score for articles with some justification and/ or explanation but it is not well - elaborated; and three is a strong score for articles with good justification and strong evidences to support their explanation. To ensure the consistency of the rating of the articles, three studies (Oxlad et al., 2008 ; Elmir et al., 2010; Mackenzie, 2014) were randomly selected and were independently evaluated by the all three reviewers based on the remaining 8 CASP questions Any differences were discussed and resolved leading to a consensus score. The score range of each article was 8-24. To allow easier comparison of quality of reviewed articles, scores 8-15 were considered as weak, 16-23 as moderate and 24 as strong (Table 1).

\section{Results}

In this study from among 324 found articles, 28 articles were found to be relevant to the aims of this study after quality appraisal. The characteristics of the 28 reviewed articles are be seen Table 2. Most of the studies were conducted in New South Wales, with a small number of studies undertaken in other states in Australia. In the 28 reviewed articles, 904 Australian women's experiences of breast cancer and associated treatments were reviewed.

Using thematic analysis, similar experiences before and during the treatment were extracted from the 28 reviewed articles, combined and grouped into five themes and thirteen sub themes (Table 3) (Braun and Clarke, 2013). Examples of excerpts for each of these emergent themes can be found in Supplementary Table 1.

\section{Theme 1: Breast cancer diagnosis and women's responses}

In this meta-synthesis, many women expressed feelings of shock, being overwhelmed, emotional upset, and disbelief at the point of their diagnosis. Some were surprised they were diagnosed with cancer despite maintaining a healthy life style such as good diet, having regular mammograms, not smoking or drinking and not experiencing high level of stress (excerpts 1.1 and 1.2). Many women reported they experienced emotional 
DOI:10.31557/APJCP.2019.20.11.3233

Lived Experience of Australian Women Living with Breast Cancer

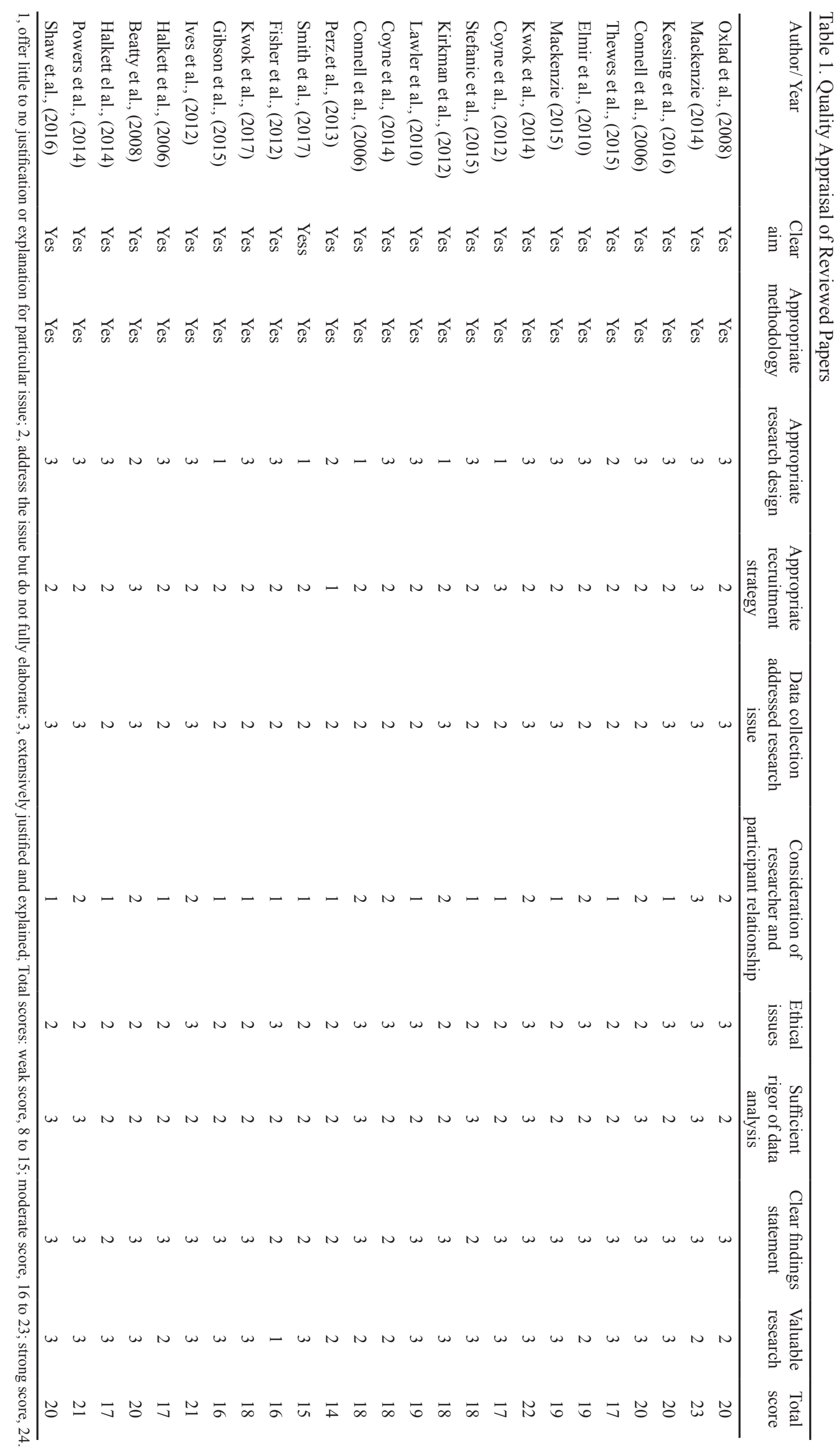




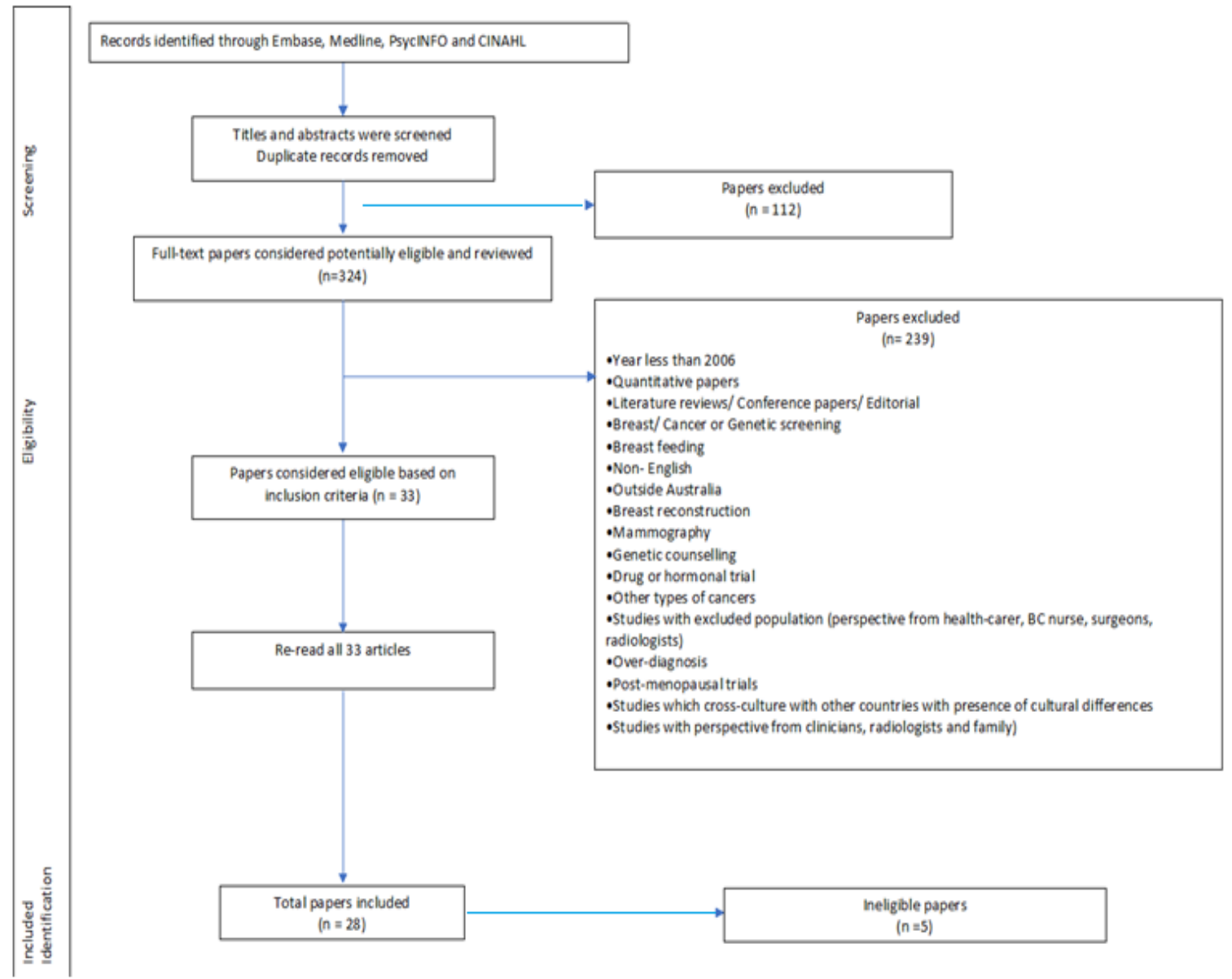

Figure 1. Search Strategy

distress on hearing what their treatment would be in the beginning (excerpts 1.3). Despite this initial shock, some women attributed to several factors for being diagnosed with breast cancer such as having existing health conditions (excerpts 1.4 and 1.5).

Interestingly, some Chinese women from Kwok and White's study culturally associated their breast cancer diagnosis as "white women's disease". Thus, they did not expect that it would happen to them.

\section{Theme 2: Emotional burden}

An emotional burden was felt by women in this meta-synthesis as a result of their breast cancer diagnosis. Two common sub themes were: fear of recurrence and thoughts of death, and the impact on pregnancy were observed across several studies (Figure 3).

Fear of recurrence and death were evident in multiple studies (Oxlad et al., 2008; Mackenzie, 2014; Keesing et al., 2016; Connell et al., 2006; Thewes et al., 2016; Elmir et al., 2010; Kwok and White, 2014; Coyne et al., 2012; Coyne and Borbasi, 2014; Connell et al., 2006; Fisher and Connor, 2012; Kwok and White, 2013; Gibson et al., 2015; Ives et al., 2012; Halkett et al., 2006; Beatty et al., 2008; Powers et al., 2014). In particular, mothers expressed their fear and concern over their children's future in the event of their death (excerpts 2.1.1). They feared they may not be able fulfil their roles and responsibilities as a mother if they died (Keesing et al., 2016; Connell et al., 2006; Coyne and Borbasi, 2014; Connell et al., 2006; Fisher and
Connor, 2012; Ives et al., 2012; Powers et al., 2014). It was interesting to note that women who practised greater mastery over fear of recurrence has less thoughts of pain and death (Thewes et al., 2016).

Several studies revealed the women's illness increased their family's practical and economic burden leaving them concerned over their family's financial status (Mackenzie, 2014; Thewes et al., 2016; Kwok and White, 2014; Coyne et al., 2012; Fisher and Connor, 2012; Kwok and White, 2013; Halkett et al., 2006). Two studies by Coyne and Borbasi (2014) and Fisher and Connor (2012) found that some women had thoughts of reducing their family's financial burden through their deaths.

Impacts on pregnancy were also apparent with women who became pregnant during their breast cancer diagnosis choosing induced abortion so they could start on their treatment immediately so that they could continue to live for their spouse and existing children (excerpt 2.2.1) (Oxlad et al., 2008, Ives et al., 2012; Kirkman et al., 2014). These studies found induced abortion can be more emotionally challenging for first time mothers diagnosed with breast cancer during their pregnancy versus non-first-time mothers with existing children (excerpt 2.2.2). There was also a natural tendency for first time mothers to worry of being able to conceive again after these abortions. For other first-time mothers who declined abortion, their cancer treatment commenced during their pregnancy. These women were worried about the effects of diagnostic tests and treatments on their unborn 


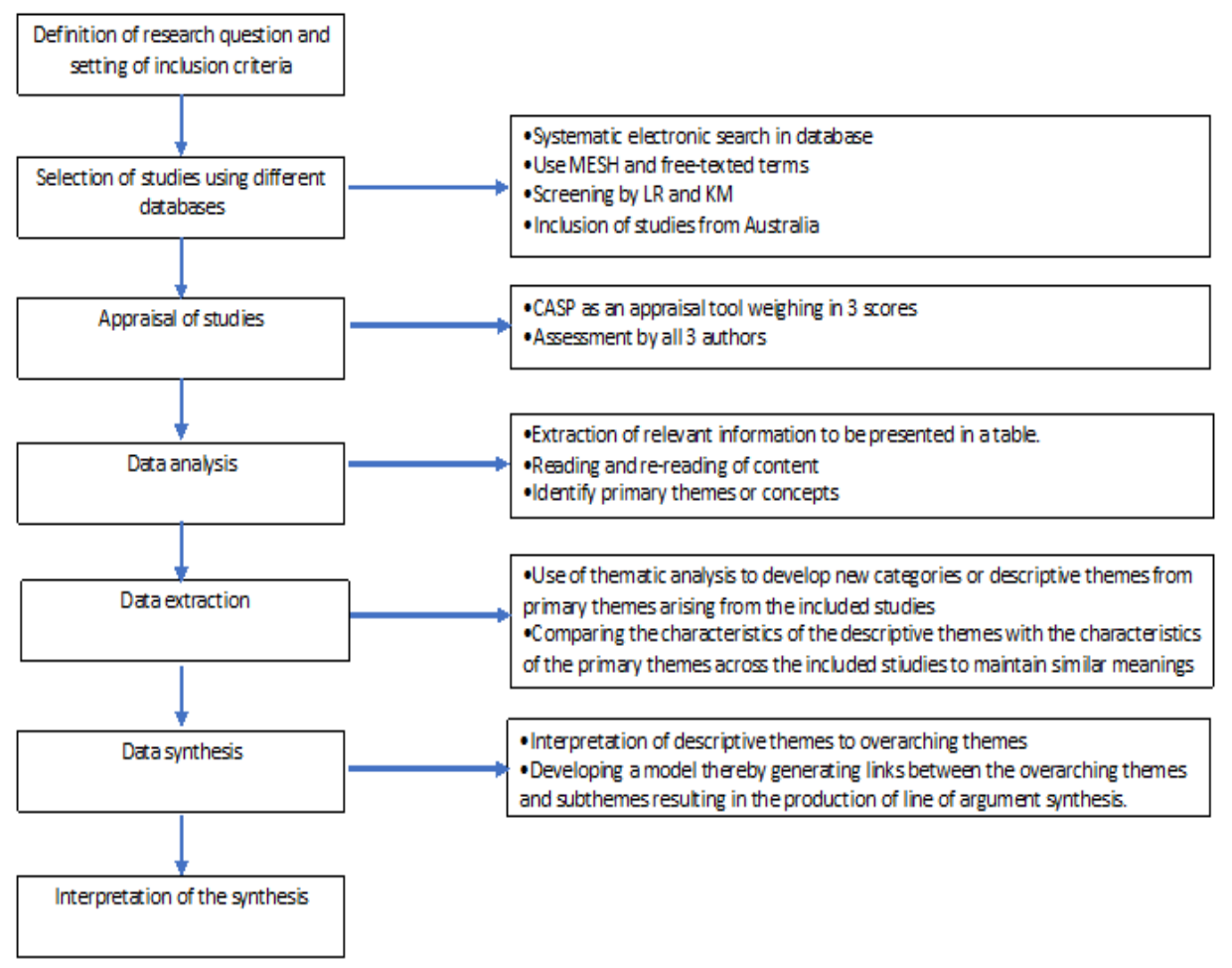

Figure 2. Study Flow Chart

child (excerpts 2.2.3). Other first- time mothers were so concerned with the effects of treatment on their unborn child, they chose to start on their treatment immediately after childbirth (excerpt 2.2.4).

Theme 3: Seeking treatment and challenges

It was apparent from 12 studies that women wanted to be part of the decision-making process which impact their fertility (Kwok and White, 2014; Kirkman et al., 2012; Lawler et al., 2010; Perz et al., 2013; Smith et al., 2017; Fisher and Connor, 2012; Kwok and Koo, 2017; Ives et al., 2012; Halkett et al., 2006; Halkett et at.,
2014; Powers et al., 2014; Kirkman et al., 2014). They often leveraged the internet to "verify information" with information provided by their healthcare providers, to ensure they correctly understood the information before making decisions (excerpts 3.1.1 and 3.1.2).

However, due to poor English proficiency, some Chinese women felt dependent on others to help them make treatment choices (excerpt 3.1.3). (Kwok and White, 2014; Kwok and Koo, 2017; Kwok and White, 2013). Support groups particularly for Chinese immigrant women were therefore seen as an important source of

Table 2. Emerging Themes and Sub-Themes

\begin{tabular}{|c|c|c|c|}
\hline Overarching Themes & Sub-themes & Descriptive themes & Primary themes \\
\hline \multirow[t]{6}{*}{$\begin{array}{l}\text { Challenges associated } \\
\text { with breast cancer }\end{array}$} & \multirow[t]{3}{*}{$\begin{array}{l}\text { Inevitable role } \\
\text { as a mother }\end{array}$} & $\begin{array}{l}\text { Protective attitude towards } \\
\text { children }\end{array}$ & $\begin{array}{l}\text { Avoid presence at children's school, shield children from hospital, } \\
\text { reveal little info on breast cancer and false display of positive strength } \\
\text { to children. }\end{array}$ \\
\hline & & Continued role as a mother & $\begin{array}{l}\text { Treatment plans according to children / family schedule, domestic } \\
\text { duties, and communication with children on BC; breast feeding }\end{array}$ \\
\hline & & Gestational Pregnancy & $\begin{array}{l}\text { Abortion, choice of surgery and unborn child's health, deferred } \\
\text { treatment }\end{array}$ \\
\hline & \multirow[t]{3}{*}{ "Who am I?" } & Body image & $\begin{array}{l}\text { Physical change, Psychological change (feel less attractive, } \\
\text { embarrassed) Social Dysfunction, reluctance to look naked at oneself, } \\
\text { loss of identity }\end{array}$ \\
\hline & & Femininity & Loss of fertility, Loss of breast (s) and Cessation of period \\
\hline & & Sexuality & $\begin{array}{l}\text { Loss of sexual interest, Sexual dysfunction and feeling unattractive to } \\
\text { partner }\end{array}$ \\
\hline \multirow{2}{*}{\multicolumn{2}{|c|}{ "So, you have survived. What's next?" }} & Attitude towards life & $\begin{array}{l}\text { Resilience and Optimism, Acceptance, Greater appreciation towards } \\
\text { life, Meaning of life, Volunteering to help others, Personal growth }\end{array}$ \\
\hline & & Self- empowerment & $\begin{array}{l}\text { Reprioritise life choices/ lifestyles and Acquire greater knowledge } \\
\text { (self- education) }\end{array}$ \\
\hline \multirow{2}{*}{\multicolumn{2}{|c|}{ Alternative coping strategies }} & Positive coping strategies & $\begin{array}{l}\text { Social distraction, Physical alteration (tattoo, wig), Personal goal based } \\
\text { strategies and Cognitive avoidance }\end{array}$ \\
\hline & & Negative coping strategies & Drug or alcohol and Use of anger \\
\hline
\end{tabular}




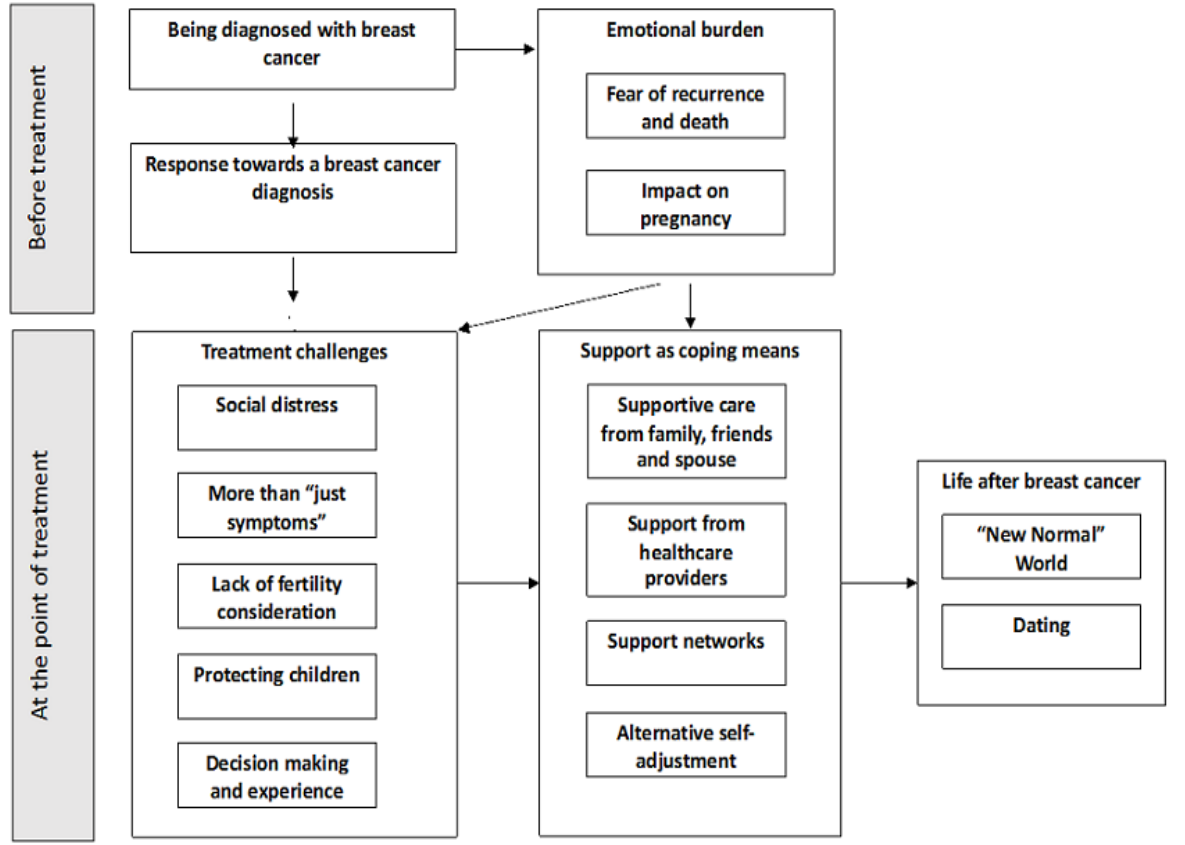

Figure 3. Model of the Lived Experiences of Australian Women Living with Breast Cancer

emotional and culturally tailored information which helped them to decide on breast cancer treatments (excerpt 3.1.4) (Kwok and White, 2014; Lawler et al., 2010; Kwok and White, 2013).

Making the right treatment decision with an intent to cure sometimes resulted in social distress which such as impact on finances and careers, which resulted in lower quality of life for many women in this meta-synthesis. An important challenge around a breast cancer diagnosis that emerged from this meta-synthesis is the financial implication of treatment. Many women funded the treatment themselves (excerpt 3.2.1). While married women faced financial difficulties for themselves and for their families (excerpt 3.2.2), younger unmarried women face unique financial difficulties including interruptions to career progression (excerpt 3.2.3).

Several studies highlighted the impact of breast cancer on body image. Many women receiving breast cancer treatment experienced changes in their physical appearance which left them shocked at the emergence of their "new identity" (Oxlad et al., 2008; Mackenzie, 2014; Perz et al., 2013; Smith et al., 2017; Fisher and Connor, 2012; Beatty et al., 2008; Powers et al., 2014; Shaw et al., 2016; Kirkman et al., 2014; Anderson et al., 2011).

Women who had a better acceptance of their body image coped better with cancer with their "new identity". Women who had a poorer conceptualisation of their body image had the potential to negatively impact themselves - physically and psychologically, as well as on the well-being of their relationships with others (excerpt 3.3.1 and 3.3.2) (Peterson et al., 2016). In another study by Shaw et al. (2016), half of the women experienced negative body image which affected their self-confidence in entering into a new relationship (excerpts 3.3.3 and 3.3.4). Kwok and White (2014) found some of their Chinese participants did not place much importance on their "new identity" and were less concerned about their body image, instead placing a greater emphasis on their survival so that they could continue their role as a mother (excerpt 3.3.5).

Younger women are often diagnosed with more aggressive breast cancer and required more intensive therapy than older women (Gnerlich et al., 2008; Sariego, 2010). The study by Anderson et al., (2011), found women $<40$ years experienced more body image disturbances when compared to older women because of early onset of menopause (excerpt 3.3.6). This led to greater sexual difficulties (excerpt 3.3.7) (Oxlad et al., 2008, Keesing et al., 2016; Perz et al., 2013; Beatty et al., 2008; Anderson et al., 2011). Some women lost their interest in sex as a result of the side effects of their treatments (excerpt 3.3.8) due to lack of libido (Perz et al., 2013; Shaw et al., 2016; Anderson et al., 2011).

Treatment of breast cancer contributed to some women's fear of being less feminine and unattractive to their partner (Oxlad et al., 2008; Elmir et al., 2010; Smith et al., 2017). Although many young women felt less feminine by the onset of early menopause, two younger women from Anderson et al., (2011)'s study, saw menopause as less distressing compared to the menstrual symptoms (excerpt 3.3.9). This same study also found older women reported greater sleep disruption post treatment compared to younger women (excerpt 3.3.10). Nonetheless, older women accepted menopause positively than the younger women.

Lack of fertility was a challenge around treatment decisions given the often rapid and distressing communication of treatment options following diagnosis. Some women could not focus on the discussion which meant they could not absorb the overwhelming information or they tended to forget the information provided to them. Within this context, women were faced with time constraints in decisions on fertility preservation before they could begin their breast cancer treatment meaning they had to make rapid decisions (Kirkman et al., 2013; Kirkman et al., 2014). However, the women who could 
DOI:10.31557/APJCP.2019.20.11.3233

Lived Experience of Australian Women Living with Breast Cancer
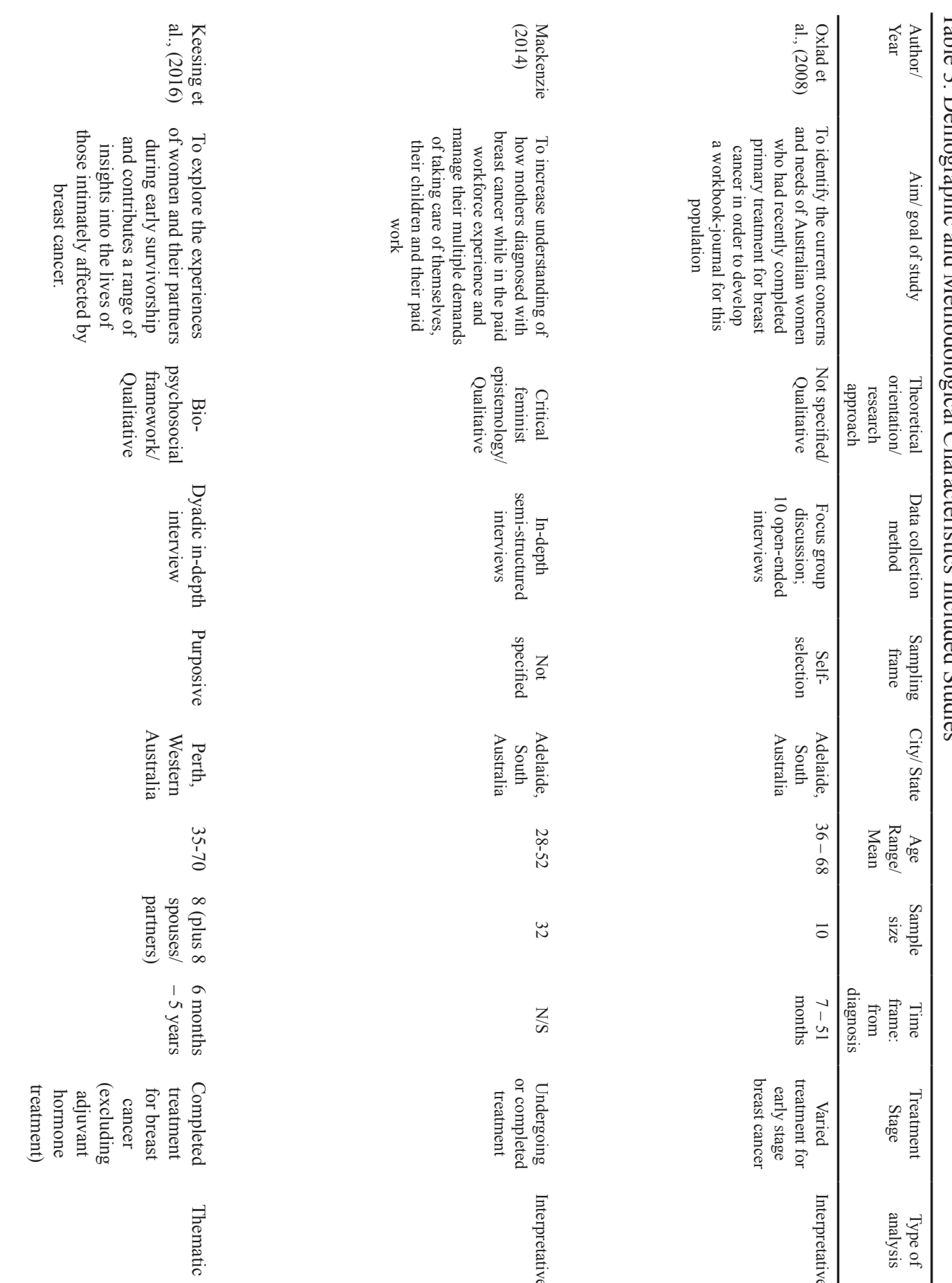

害|

产

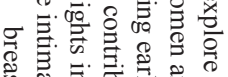

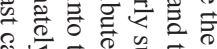

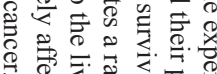

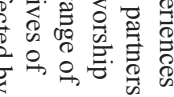

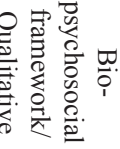

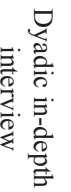

竞:

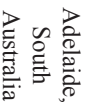

总

嵓

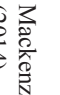

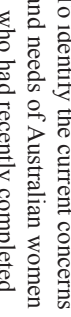

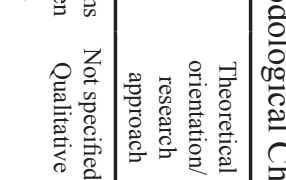

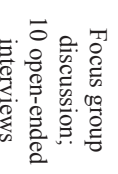

氕

峲

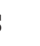

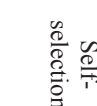

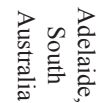

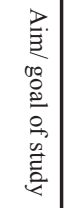




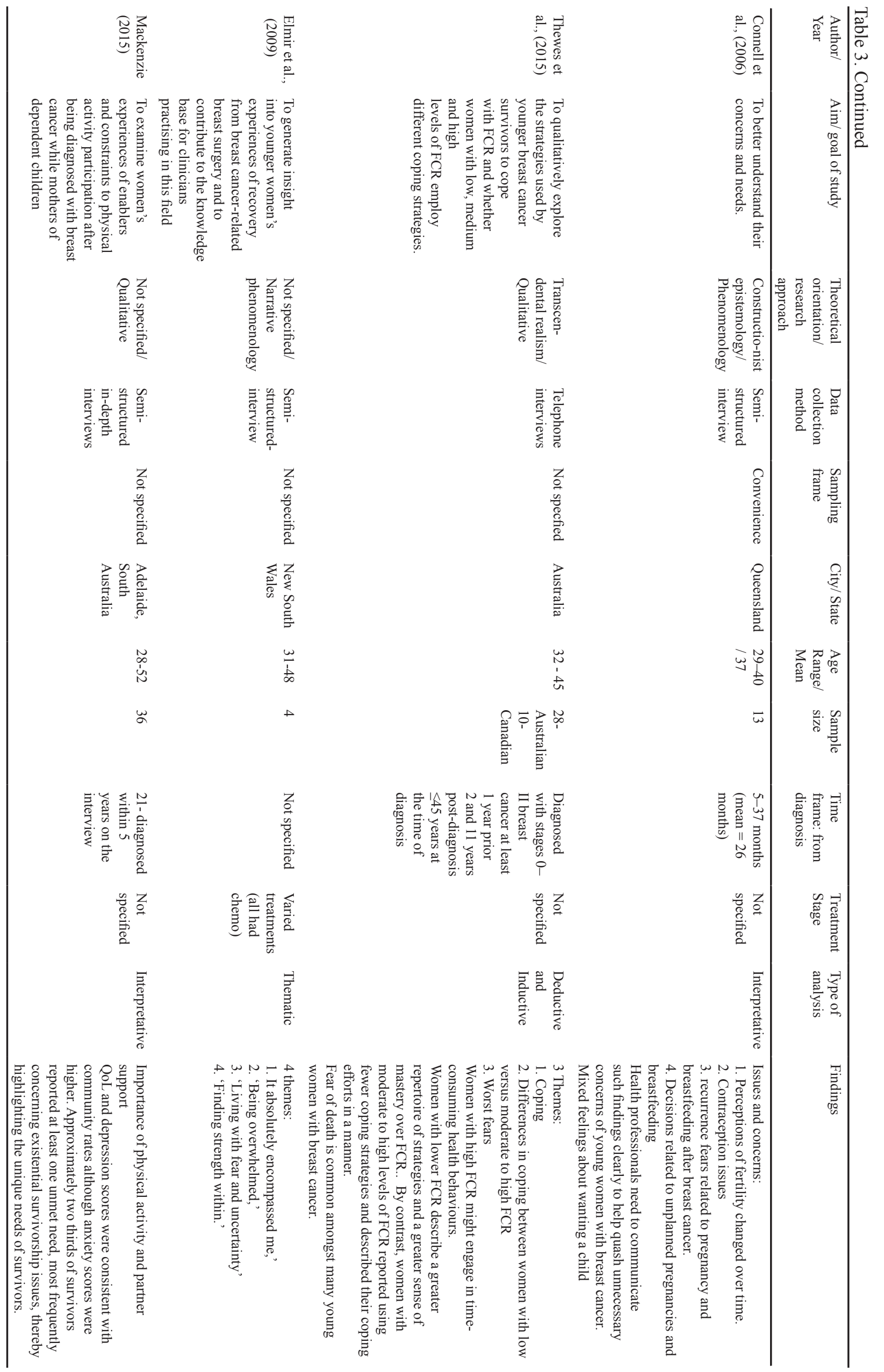

3240 Asian Pacific Journal of Cancer Prevention, Vol 20 
DOI:10.31557/APJCP.2019.20.11.3233

Lived Experience of Australian Women Living with Breast Cancer

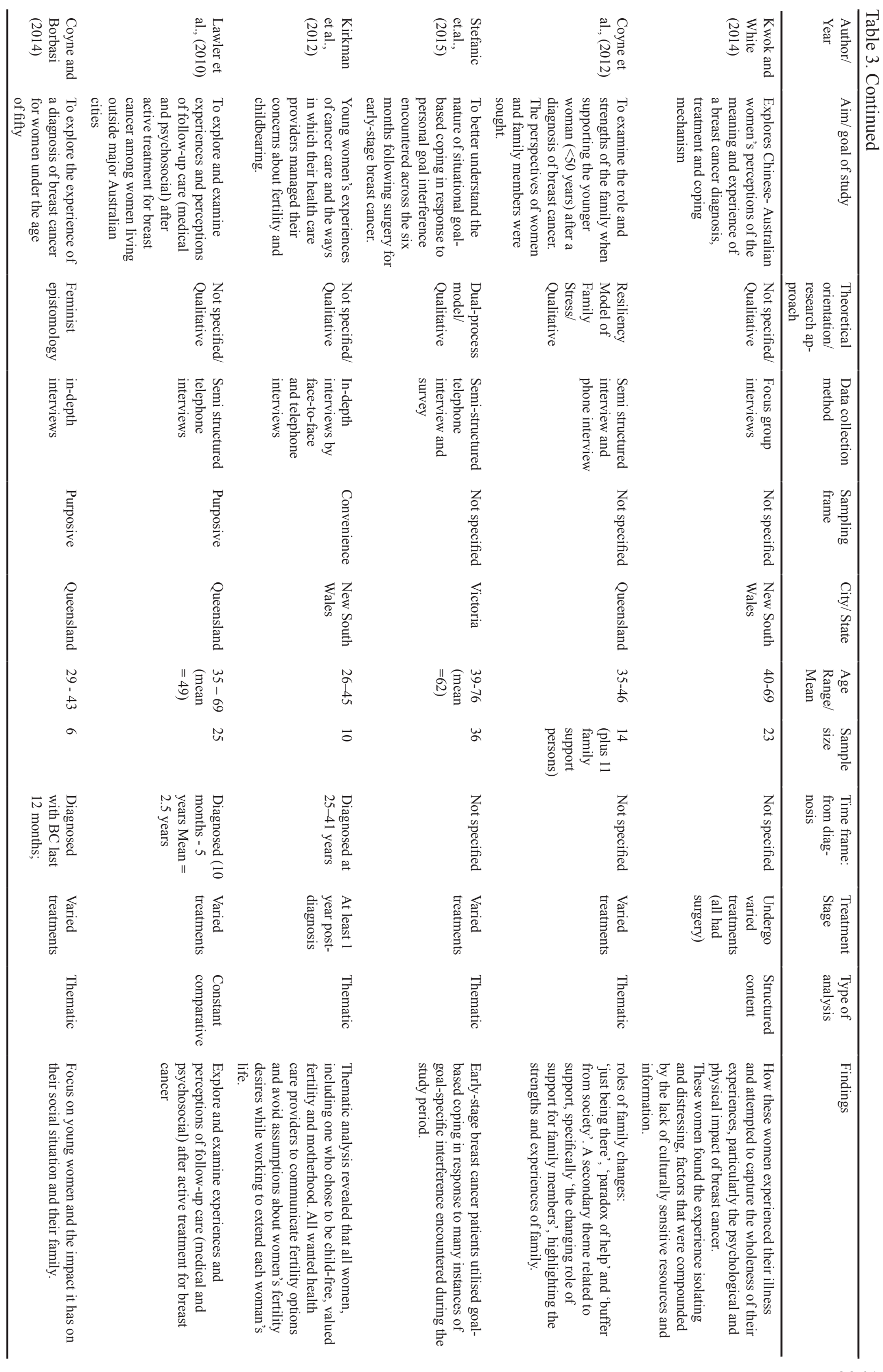

Asian Pacific Journal of Cancer Prevention, Vol 20 


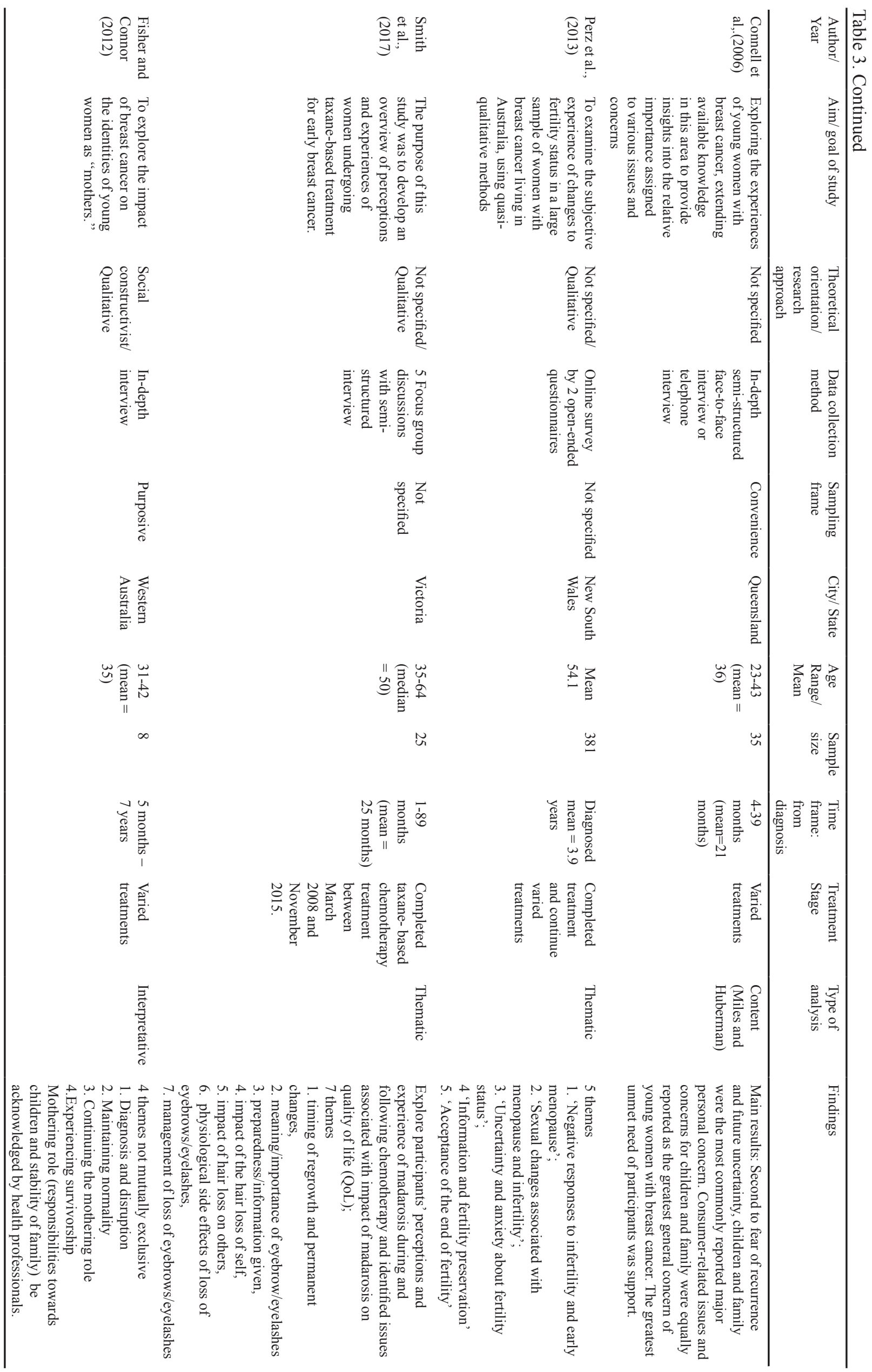

3242 Asian Pacific Journal of Cancer Prevention, Vol 20 
DOI:10.31557/APJCP.2019.20.11.3233

Lived Experience of Australian Women Living with Breast Cancer

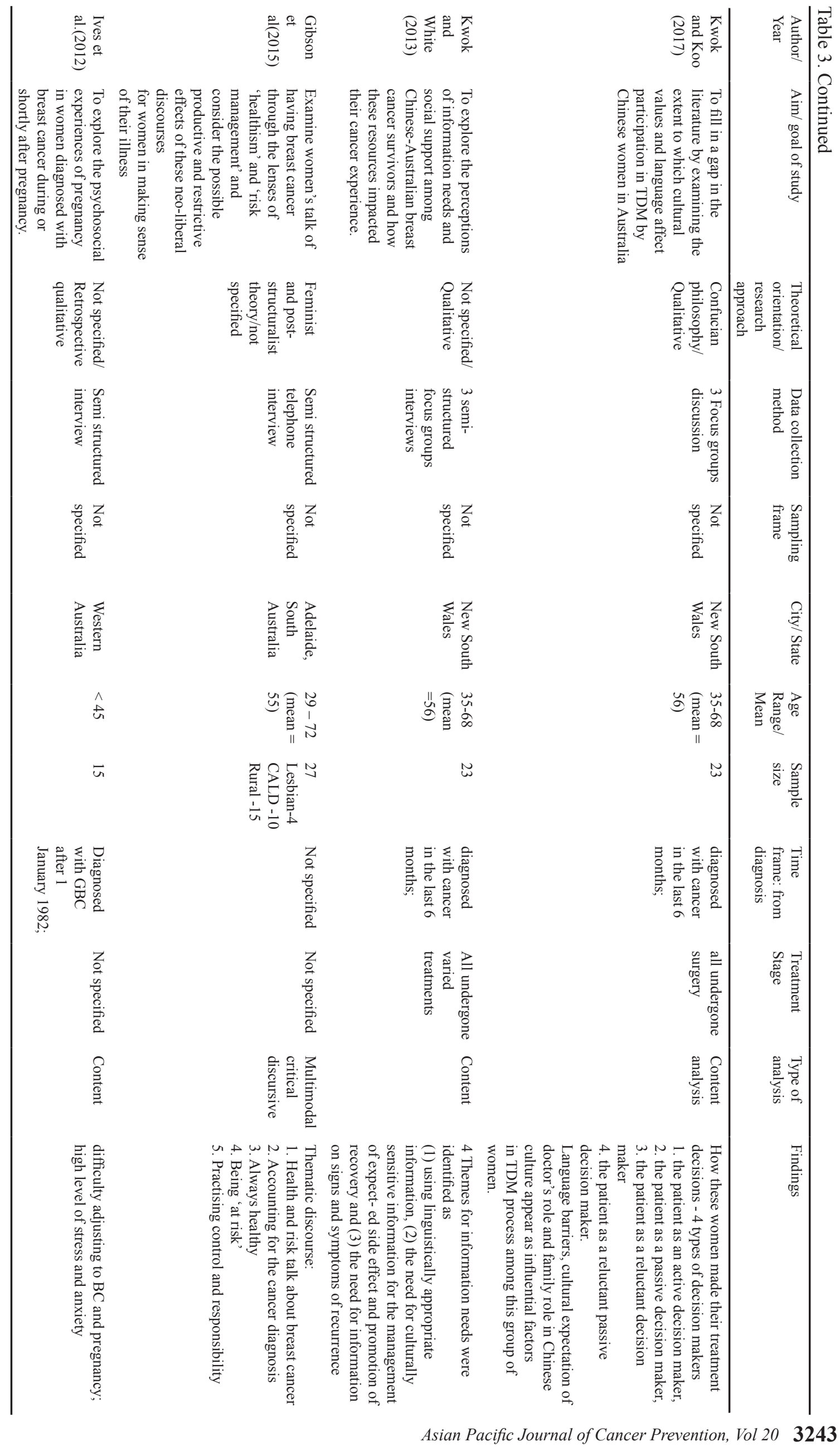




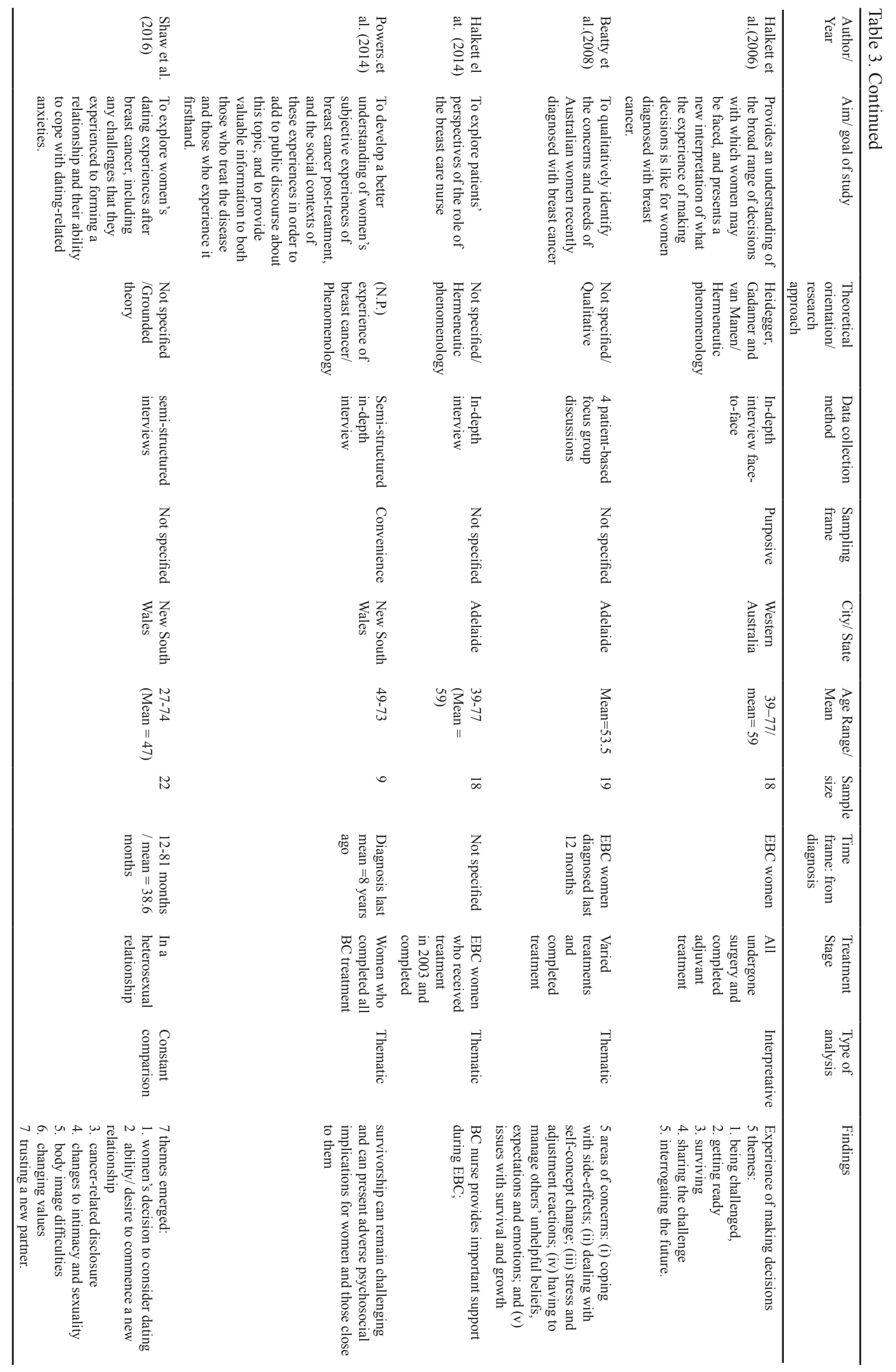

3244 Asian Pacific Journal of Cancer Prevention, Vol 20 
DOI: 10.31557/APJCP.2019.20.11.3233

Lived Experience of Australian Women Living with Breast Cancer

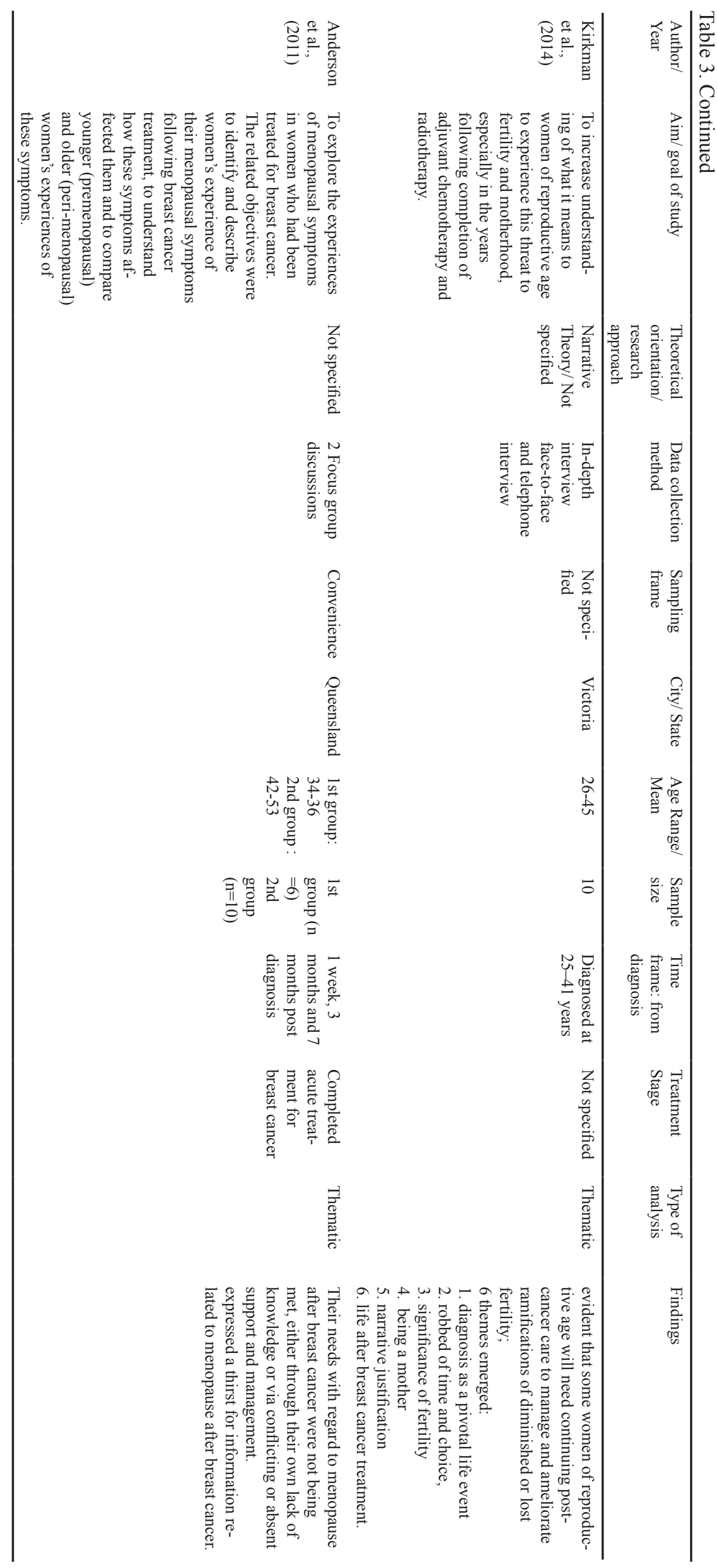


not make these rapid decisions displayed "submissive" behaviour by accepting treatment decision exercised by their doctors which as a result affected their fertility (Kwok and White, 2014; Kirkman et al., 2012; Lawler et al., 2010; Smith et al., 2017; Kwok and Koo, 2017).

Notably, many women were not aware they needed to take steps to preserve their fertility (Kwok and White, 2014; Kirkman et al., 2012; Perz et al., 2013; Kwok and Koo, 2017; Halkett et al., 2006; Halkett el at., 2014; Anderson et al., 2011). Some women reported that fertility preservation was not discussed, with their continuing fertility assumed by doctors (Kirkman et al., 2012; Perz et al., 2013; Fisher and Connor, 2012; Kirkman et al., 2014). Some older women also felt their fertility was assumed by healthcare providers before the start of treatment (excerpts 3.4.1, 3.4.2, 3.4.3 and 3.4.4), leading to inaccurate decision-making resulting in infertility. Further, despite good support and awareness provided by some healthcare providers, other women chose not to participate in any fertility preservation based on their assumption they would regain their fertility after breast cancer treatment (Connell et al., 2006; Perz et al., 2014).

Lack of support for young women in hospital was also reported. Some women shared their frustration at the lack of empathy from male healthcare providers (excerpt 3.4.5), given their lack of personal experience of treatments effect such as hot flushes due to menopause onset.

Being a mother also meant the protection of children had an impact with many mothers taking steps to protect their children emotionally. Even if mothers were depressed and concerned over the care of their children by the uncertainty of treatment outcomes they also wanted to shield their children from emotional trauma by maintaining a positive attitude in the presence of their children. This protective attitude included false displays of positive strength, shielding children from visits to oncological wards and revealing little information to ensure that the normality of their children's life was maintained (excerpt 3.5.1).

Mothers also attempted to protect their children from emotional impact and/or embarrassment due to changes in their body (excerpt 3.5.2). For example, Fisher and Connor, (2012) and Kirkman et al., (2014) found mothers avoided being at their children's school as their hair loss may impact children's normality at school. Mothers also carried out their treatments according to their children and family schedules to maintain normality (Mackenzie, 2014, Mackenzie, 2015; Coyne and Borbasi, 2014; Fisher and Connor, 2012; Kwok and White, 2013).

\section{Theme 4: Support as coping means}

Women in this meta-synthesis reported that emotional and practical support helped them to cope with the psychosocial impacts of treatments (excerpts 4.1.1 and 4.1.2).

The majority of women felt a major impact on their ability to carry out their daily household chores, taking care of their children, and attending to their families. For many, their inability to work efficiently due to physical weakness was a constant reminder of their illness. For women with extended families, the parents and sisters of the family usually assisted the women with their household responsibilities. However, for other women such as migrant women, support from extended family was limited and they had to depend on spousal assistance (excerpts 4.1.3 and 4.1.4). .

Many women acknowledged that having a supportive relationship with a spouse (excerpt 4.1.5) was a critical ingredient to their physical and mental health as it buffers a woman's negative feelings such as feeling of stigma, anxiety and depression (Mackenzie, 2015; Kwok and White, 2014; Coyne et al., 2012; Halkett et al., 2006). Spouses were also reported to hide their feelings (excerpts 4.1.6 and 4.1.7) to provide emotional reassurance to women undergoing treatment (Keesing et al., 2016; Coyne et al., 2012). in other cases, some spouses were initially supportive but became less so in the latter stages of their cancer journey (excerpt 4.1.8), especially with the care of children.

Interestingly, some women felt better supported emotionally and informationally by their healthcare providers which led to them feeling safer when in hospital (Elmir et al., 2010; Kirkman et al., 2012; Lawler et al., 2010; Halkett et al., 2006; Halkett el at., 2014; Powers et al., 2014). Some women felt that interacting with healthcare providers positively impacted on them which helped them to cope better with their cancer (excerpt 4.2.1 and 4.2.2). On the flip side, some women felt their emotional safety net was removed once their treatment was over (excerpts 4.2.3 and 4.2.5).

Chinese individuals in this study placed great respect and trust in the expert knowledge of their doctors. Hence, these women place great importance on advice provided by the healthcare providers which in turn helped emotionally support them during their treatment journey (excerpt 4.2.4).

Younger women, on the other hand, found the informational support provided by breast care nurses during treatment was calibrated more for older women and hence, some women sought additional internet support which was more calibrated to their age (Keesing et al., 2016; Lawler et al., 2010; Fisher and Connor, 2012; Gibson et al., 2015; Halkett et al., 2006; Anderson et al., 2011).

Support networks and groups were another platform to emotionally support women during their diagnosis and treatment. Support groups were also important in gaining some sort of normalcy - reducing stigma and allowing women to freely express themselves without feeling shamed (Luoma and Platt, 2014). However, some women did not want to attend support groups as they were not prepared to share their negative experience of breast cancer, fearing such support groups might make them feel more negative (Oxlad et al., 2008; Shaw et al., 2016).

Although receiving support was seen as being vital in ensuring women cope well during their treatment, it was important for women to take some responsibility for themselves through some self-adjustments. Some women adopted positive self-adjustment strategies (excerpt 4.4.1) whereas others adopted negative self-adjustment strategies journey (Corbin et al., 2013; Powers et al., 2014; Thewes et al., 2016; Shaw et al., 2016; Sinha, 2008; Smith et al., 
2017).

\section{Theme 5: Life after a breast cancer diagnosis}

Studies revealed that participants' experience of diagnosis and treatment of breast cancer were a turning point in their lives, with the creation of a "new normal world". This meant recognition and acceptance of breast cancer as now being part of their life, in other words survivorship.

Women defined survivorship to what life was in its everydayness after diagnosis. This meta-synthesis allowed us to gain insight into this new perspective of their lives and understand their "new normal" world on one's own terms by creating new meaning of life. This allowed women to have greater appreciation towards life moving forward (excerpts 5.1.1 and 5.1.2).

Many women developed self-empowerment by taking greater control of their life and reprioritising their life choices. Changing their diet, acquiring greater knowledge through self-education, volunteering to help others, taking part in social events, and choosing not to be in relationship were some of the choices women exercised (excerpt 5.1.3).

Seeking a new relationship became particularly challenging for single women, with some women trying online dating (excerpt 5.2.1). as they started feeling lonely (Oxlad et al., 2008; Beatty et al., 2008; Shaw et al., 2016). This was necessary as undergoing treatment or recovering post-surgery meant meeting new partners at social events was not be feasible for some women.

For other women, concerns on future relationships such as fear of rejection from potential partners after the disclosure of a breast cancer diagnosis or physical sequalae such as post-surgery scars/infertility issues as well as trust issues was the motivation for them to use online dating as an alternative strategy so they could feel confident around these issues before meeting potential new partners face-to-face (Perz et al., 2013; Shaw et al., 2016; Kirkman et al., 2014).

Some women dated selectively by seeking relationships with men with similar cancer experiences, hoping the men would be able to understand their cancer journey more easily. This gave an assurance to women that their potential partners may understand their similar cancer journey and associated challenges (excerpt 5.2.2).

\section{Discussion}

There is currently no meta-synthesis focused on the lived experiences of symptoms of breast cancer and body image among Australian women diagnosed with breast cancer. This meta-synthesis adds to this evidence-base with an in-depth exploration of how women are emotionally supported during and after treatment.

Findings from this meta-synthesis suggest most women experience high levels of distress following a breast cancer diagnosis and as a consequence had informational emotional and financial support needs. Being pregnant or a mother added to the complexities around the support needed with unmet needs around fertility decisions highlighted. Many women experienced body image disturbances which impacted on them
Lived Experience of Australian Women Living with Breast Cancer

emotionally and their relationships with others. However, many women reported received support from their spouses or healthcare providers.

While some of the women included in this meta-synthesis opted to receive treatment during their pregnancy, many chose to start treatment after the birth of their child, fearing possible harm to their unborn baby. These findings show mothers are concerned for their unborn child above all else, including their own health, demonstrated through the value they place on the child (Larson, 1998). Delays in treatment due to the possible risks to unborn children, are at odds with current evidence which suggests chemotherapy only threatens abnormal foetal development and miscarriage if given in the first trimester (Kimby et al., 2004; Amant et al., 2012). However chemotherapy given in the second and/or third trimester may be associated with low birth weight. Choice of treatments in certain stages of pregnancy and concerns on breast cancer should be discussed and be tailored to the individual using a multidisciplinary approach where the team should be focussed both breast cancer treatment and pregnancy care so that the best outcome can be achieved versus potential poorer outcomes due to delayed treatment.

Concern for children also extended beyond pregnancy, with mothers aiming to ensure daily normal routines were continued with minimal disruption to children during treatment. This was to ensure children were provided with caring and protective environments while not being exposed to emotions and illness. In Barnes et al., 's study, parents gave clear reasons for telling or hiding from their children about their diagnosis. Further, preventing children from becoming distressed and preservation of family time due to uncertainty for the future were reasons for withholding information about illness (Asbury et al., 2014). Additional support for mothers following their diagnosis may be warranted through the use of patient education for parents on managing communication with children after diagnosis and during treatment. In addition, support programmes could be extended to offer children and the wider family to facilitate greater support of 'normal' routine in families.

Many women in this meta-synthesis reported regrets of not pursuing fertility treatment either due to feeling unprepared or lack of appropriate and timely information to make decisions around choice of treatment. The reported low rates of discussion on fertility preservation with healthcare providers highlights the unmet needs of patient around their fertility. Women also indicated that assumptions around their fertility should not be made by healthcare providers even if they are trying to initiate treatment quickly as quality of survivorship and increase distress can be negatively affected due to loss of fertility. Healthcare providers should also have an understanding about the role of women's concerns and fertility and should use their experiential knowledge coupled with patient-education tools to inform and shape a patient's right choice of treatment decision.

Expediency of treatment to optimise good outcomes can also affect women's sexuality and self-esteem due to body image disturbances, which may ultimately affect quality of survivorship particularly for women seeking 
new relationships. As different women have different pace of adjustments, healthcare providers must give attention to these adjustments. It is likely women's body image disturbances are related to sexual problems as a result of treatment for breast cancer. It is also possible each woman's sexual adjustment is different and is dependent on body perceptions together with her sexuality (Sheppard and Ely, 2008). In western cultures, women generally have a strong attachment to their breasts as they define sexuality and femininity (Schmied and Lupton, 2001). Lack of sexual adjustment causes lower self-esteem and altered self-concept of body resulting in negative body image which may affect existing relationships or ability to form relationships. Tailored counselling surrounding body image disturbances unique to each women's situation could be made part of treatment programmes to assist women in understanding her feelings towards her diagnosis (Nápoles-Springer et al., 2008).

Fortunately, many women described support networks that can help them cope with their diagnosis. For example many of the women in this meta-synthesis acknowledged their spouse was their main caregiver who took care of them and helped them to cope with their illness (Hunt, 2003). Caregivers form an important part of cancer team care and the relationship between caregiver and patient is intertwined (Litzelman et al., 2016). Some women also acknowledged their spouses would try to additionally support them by hiding their own feelings despite being distressed by the breast cancer diagnosis and treatment (Ohayon et al., 2010). Negative psychological distress may negatively impact on the caregiving experience, however, leading to poorer health outcomes for the patient when caregivers feel overwhelmed or burdened. Although studies have highlighted how women receive support from their spouses, there are no findings which demonstrate how spouses are supported in protecting women from psychological distress. This is an important of lack of support for spouses which may have clinical implications on the well-being of women undergoing breast cancer. Findings from this meta-synthesis suggest recognition of the emotional needs of spouses and other family members in conjunction with the patient's cancer experience is needed. Potentially, family counselling programmes could become part of practice guidelines.

Positively, many women also felt emotionally supported and reassured by their healthcare providers during treatment. Other women, however, highlighted low rates of discussion for example around and felt rushed in treatment decision-making by healthcare providers following their diagnosis due to limited time frames. There appear to be inconsistencies in the emotional and informational support received at the point of diagnosis and during treatment. Clear guidelines on how healthcare providers support women better emotionally appear needed for example by giving them adequate space to make decisions despite short timeframes and by aiming to understand each patient's contextual needs.

Nonetheless many women in this meta-synthesis believe the support provided by healthcare providers during breast cancer diagnosis promoted well-being and coping (Arora et al., 2007; Street, 2007). Conversely, however, Landmark et al.,'s study (2002), found there could be increased emotional burden among women with a poorly communicated diagnosis and where information related to diagnosis and treatment was poorly coordinated. This study also found that one third of healthcare providers were not trained to communicate women's diagnosis appropriately. Communication training programmes for healthcare providers to enable them to deliver diagnoses should therefore be obligatory for those working in oncology settings.

In conclusion, although many women were emotionally supported following their diagnosis, there are still areas where women could be better supported. This may include support when having to tell children of their breast cancer diagnosis, provision of ongoing support for caregivers of women with breast cancer, provision of consistent support at the time of diagnosis and during treatment as well as standard discussions of fertility in a timely manner by healthcare professionals.

\section{Acknowledgments}

This work forms part of a PhD thesis and did not need ethics approval due to being a secondary analysis of existing literature. There are no conflicts of interest.

\section{Limitations}

This meta-synthesis has several limitations. First, only English language studies were included, It is possible cultural studies in other languages were overlooked. Second, most of the included studies did not investigate emotional support needs for caregivers. This meta-synthesis could therefore not consider the whole family as a unit of care, just the patient. Third, most women included here were mothers, with many reporting higher distress levels and concerns about their children therefore findings may not be generalisable to non-mothers.

\section{Funding statement}

No funding was received for this project

\section{References}

Australian Institute of Health and Welfare (AIHW). Cancer in Australia 2019 [Available from: https://www.aihw.gov.au/ getmedia/8c9fcf52-0055-41a0-96d9-f81b0feb98cf/aihwcan-123.pdf.aspx?inline $=$ true.]

Amant F, Loibl S, Neven P, Van Calsteren K (2012). Malignancies in Pregnancy. Breast cancer in pregnancy. Lancet Oncol, 9815, pp.580-7.

Arora NK, Finney RLJ, Gustafson DH, Moser R, Hawkins RP. Perceived helpfulness and impact of social support provided by family, friends, and health care providers to women newly diagnosed with breast cancer. Psychooncology, 16, 474-86.

Asbury N, Lalayiannis L, Walshe A (2014). How do I tell the children? Women's experiences of sharing information about breast cancer diagnosis and treatment. Eur J Oncol Nurs, 18, 564-70.

Beatty L, Oxlad M, Koczwara B, Wade TD (2008). The psychosocial concerns and needs of women recently diagnosed with breast cancer: a qualitative study of patient, nurse and volunteer perspectives. Health Expect, 4, 331-42.

Barnes J, Kroll L, Burke O, Lee J, Jones A, Stein A (2000). 
Qualitative interview study of communication between parents and children about maternal breast cancer. $B M J$, 321, 479 - 82 .

Breast Cancer Network Australia. Current breast cancer statistics in Australia 2019 [Available from: https://www.bcna.org.au/ media/6101/bcna-2018-current-breast-cancer-statistics-inaustralia-31jan2018.pdf

Cebeci F, Yangin HB, Tekeli A (2011). Life experiences of women with breast cancer in south western Turkey: A qualitative study. Eur J Oncol Nurs, 16, 406-12.

Clarke V, Braun V (2013). Teaching thematic analysis: Overcoming challenges and developing strategies for effective learning. Psychologist, 26, 120-3.

Connell S, Patterson C, Newman B. Issues and concerns of young Australian women with breast cancer. Support Care Cancer. 2006;14:419-26.

Coyne E, Borbasi S (2014). Holding it all together: Breast cancer and its impact on life for younger women. Contemp Nurse, 2,157-69.

Coyne E, Wollin J, Creedy DK (2012). Exploration of the family's role and strengths after a young woman is diagnosed with breast cancer: Views of women and their families. Eur J Oncol Nurs, 16,124-30.

Elmir R, LJackson D, Beale B, Schmied V (2010). Against all odds: Australian women's experiences of recovery from breast cancer. J Clin Nurs, 19, 2531-8.

Fisher C, O'Connor M (2012). "Motherhood" in the context of living with breast cancer. Cancer Nurs, 2.

Gibson AF, Lee C, Crabb S (2015). 'Take ownership of your condition': Australian women's health and risk talk in relation to their experiences of breast cancer. Health, Risk \& Society, 2,132-48.

Halkett G, Arbon P, Scutter S, Borg M (2006). The role of the breast care nurse during treatment for early breast cancer: The patient's perspective. Contemp Nurse, 1,46-57.

Hasson-Ohayon I, Goldzweig G, Sela-Oren T, et al (2015). Attachment style, social support and finding meaning among spouses of colorectal cancer patients: gender differences. Palliative Support Care, 13, 527-35.

Hunt CK (2003). Concepts in Caregiver Research. J Nurs Scholarsh, 35, 27-32.

Ives A, T M, Saunders C (2012). The experience of pregnancy and early motherhood in women diagnosed with gestational breast cancer. J Psychosoc Oncol, 21, 754-61.

Joulaee A, Joolaee S, Kadivar M, Hajibabaee F (2012). Living with breast cancer: Iranian women's lived experiences. Int Nurs Rev, 59, 362-8.

Keesing S, Rosenwax L, McNamara B (2016). A dyadic approach to understanding the impact of breast cancer on relationships between partners during early survivorship. BMC Women's Health, 57, 1-14.

Kimby E, Sverrisdottir A, Elinder G (2004). Safety of rituximab therapy during the first trimester of pregnancy: a case history. Eur J Haematol, 72, 292-5.

Kwok C, White K (2014). Cultural and linguistic isolation: The breast cancer experience of Chinese-Australian women - A qualitative study. Contemp Nurse, 39, 85-94.

Lachal J, Revah-LevyA, Orri M, Moro MR (2017). Metasynthesis: an original method to synthesize qualitative literature in psychiatry. Front Psychiatry, 8, 269.

Landmark BT, Strandmark M, Wahl A (2002). Breast cancer and experiences of social support. In-depth interviews of 10 women with newly diagnosed breast cancer. Scand $J$ Caring Sci, 16, 216 - 23.

Larson E (1998). Reframing the meaning if disability to families: The embrace of paradox. Soc Sci Med, 47, 865- 75.

Litzelman K, Kent EE, Mollica M, Rowland JH (2016). How does caregiver well-being relate to perceived quality of care in patients with cancer? Exploring Associations and Pathways. J Clin Oncol, 34, 3554-61.

MacKenzie C R (2014). 'It is hard for mums to put themselves first': How mothers diagnosed with breast cancer manage the sociological boundaries between paid work, family and caring for the self. Soc Sci Med, 117, 96-106.

Moolchaem P, Liamputtong P, O'Halloran P, Muhamad R (2015). The lived experiences of transgender persons: A meta-synthesis. J Gay Lesbian Soc Serv, 2, 143-71.

Napoles-Springer AM, Ortiz C, O'Brien H, Diaz-Mendez M (2009). Developing a culturally competent peer support intervention for Spanish-speaking Latinas with breast cancer. J Immigr Minor Health, 11, 268-80.

Oxlad M, Wade TD, Hallsworth L, Koczwara B (2008). 'I'm living with a chronic illness, not dying with cancer': a qualitative study of Australian women's self-identified concerns and needs following primary treatment for breast cancer. Eur J Cancer Care, 17, 157-66.

Perreault A, Bourbonnais FF (2013). The experience of suffering as lived by women with breast cancer. Int J Palliat Nurs, 11, 510-9.

Perz J, Ussher J, Gilberte E (2014). Loss, uncertainty, or acceptance: subjective experience of changes to fertility after breast cancer. Eur J Cancer Care, 23, 514-22.

Powers N, Gullifer J, Shaw R (2014). When the treatment stops: A qualitative study of life post breast cancer treatment. $J$ Health Psychol, 7, 1371-82.

Schmied V, Lupton D (2001). Blurring the boundaries: breastfeeding and maternal subjectivity. Sociol Health Illn, 23, 234 - 50.

Sheppard LA, Ely S (2008). Breast cancer and sexuality. Breast $J, 14,176-81$.

Stout NL, Binkley JM, Schmitz KH, et al (2012). A prospective surveillance model for rehabilitation for women with breast cancer. Am Cancer Soc, 118, 2191 - 200.

Street Jr RL, Makoul G, Arora NK, Epstein RM (2009). How does communication heal? Pathways linking clinician-patient communication to health outcomes. Patient Educ Couns, 74, 295-301.

Thewes A, Lebel S, Leclair CS, Burtow P (2016). A qualitative exploration of fear of cancer recurrence (FCR) amongst Australian and Canadian breast cancer survivors. Support Care Cancer, 24, 2269-76.

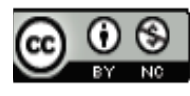

This work is licensed under a Creative Commons AttributionNon Commercial 4.0 International License. 